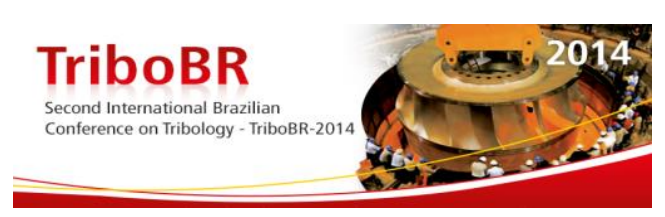

\title{
SURFACE MICROHARDNESS OF AISI 4140 STEEL NITRIDED DURING ELECTRIC DISCHARGE MACHINING*
}

\author{
Rogério Felício dos Santos ${ }^{1}$ \\ Ernane Rodrigues da Silva ${ }^{2}$ \\ André Rezende Figueiredo Oliveira ${ }^{3}$ \\ Henara Lillian Costa 4 \\ Alberto Arnaldo Raslan ${ }^{5}$
}

\begin{abstract}
Nitriding of metallic materials using electric discharges generated during electric discharge machining (EDM) is a recently developed technique. The aim of this paper was to correlate mechanical properties of a nitrided layer produced in AISI 4140 steel by EDM nitriding with the type and amount of nitrides. A conventional die-sinking EDM equipment and electrolytic copper electrodes were used to generate the electric discharges. The electrolyte was a solution of urea in deionized water. Knoop microhardness profiles assessed the variation of hardness along the nitrided layer, whereas the elastic modulus of this layer was measured using nanoindentation tests. Optical microscopy and X-ray diffraction (XRD) were used to characterize the nitrided surface. The results showed the formation of a nitrided layer containing iron nitrides with average thickness of around $25 \mu \mathrm{m}$. The amount of nitrides reduced from the surface towards the centre and these results correlated well with microhardness profiles obtained.
\end{abstract}

Keywords: Nitriding; AISI 4140 steel; EDM; Urea; Knoop microhardness.

1 Dr., Centro Tecnológico Federal de Minas Gerais, Belo Horizonte, Brazil.

2 Dr., Centro Tecnológico Federal de Minas Gerais, Belo Horizonte, Brazil.

3 M. Sc., Universidade Federal de Uberlândia, Uberlândia, MG, Brazil.

4 PhD, Associate Professor, Universidade Federal de Uberlândia, Uberlândia, MG, Brazil.

5 Dr., Full Professor, Universidade Federal de Uberlândia, Uberlândia, MG, Brazil.

\footnotetext{
* Technical contribution to the $2^{\text {nd }}$ International Brazilian Conference on Tribology - TriboBR 2014, November $3^{\text {rd }}$ to $5^{\text {th }}$, 2014, Foz do Iguaçu, PR, Brazil.
} 


\section{INTRODUCTION}

Electrical discharge machining (EDM) is an essentially thermal process. The energy source originates from electrical discharges generated in a plasma channel between two electrodes, the tool and the workpiece, submersed within a dielectric fluid. High temperatures, between 8,000 and $10,000^{\circ} \mathrm{C}$, are generated within the plasma channel. Copper and graphite are normally used as electrodes. The most common dielectric fluids are mineral oils, which provide hydrogen ions into the plasma channel. When the plasma channel is dissipated, the temperature in the workpiece reaches values above $15,000^{\circ} \mathrm{C}$, and pressures of the order of 200 bar are generated [1] due to the collision of ions and electrons with the electrode and workpiece. The combined effect of material fusion and movement due to the dielectric fluid turbulence is responsible for material removal in EDM [1].

Due to very high temperatures involved in EDM, the incorporation of elements from the electrode and/or dielectric fluid is unavoidable, even using standard machining conditions, although at a low level [2]. This fact has inspired work to investigate the possibility of enriching metallic surfaces with alloying elements using EDM [3]. In one approach, insoluble powders are incorporated in the dielectric fluid [3-5]. For example, SiC powder was mixed to deionized water during EDM of Ti-6Al-4V surfaces [4]. After machining, SiC particles were detected in the recast layer and the authors indicated the potential of the process to be also used as a surface alloying technique. Similarly, surface enrichment of die steels was investigated by mixing W, $\mathrm{Si}$ and graphite powders in the dielectric fluid (kerosene and commercial EDM oil) during EDM [5]. However, since the recast layer is very porous and brittle, and therefore it is normally removed after machining, when enrichment occurs only within this layer it may not be very useful. One potential use for this enrichment technique could be applications where surface texturing combined with surface hardening is beneficial [6]. In another approach, compacted powder electrodes are used during EDM intending to incorporate particles from the electrode onto the workpiece surface [2,3,7,8], such as WC/Co onto H13 steel [2], Si onto aluminium [7], and TiC onto high speed steel [8]. This process has been called electrical discharge alloying [7] or electrical discharge coating (EDC) [8]. A third possibility has been the combination of both adding powders to the dielectric fluid and using powder electrodes [3].

An apparently similar technique was used by Yan et al. [9], who diluted urea at a proportion of $10 \mathrm{~g} / \mathrm{l}$ in deionized water to use as dielectric fluid. During EDM of Ti6AI4V workpieces, surface hardening was detected and attributed to the formation of titanium nitrides. Although their experimental characterization did not allow investigating in detail the mechanisms involved in this hardening, it was possible to envisage the potential advantages of their technique, since the source of alloying element was dissolved in the dielectric fluid, which probably increases its availability within the plasma channel.

Our group has invested great effort in investigating nitrogen enrichment of metallic surfaces using a similar technique [10-13]. Initially, experimental evidence of nitriding of Ti6Al4V was obtained [10], which was later extended to AISI 4140 steels [11-13]. For nitriding of AISI 4140 steel by EDM, the formation of a uniform nitride layer with thickness between 20 to $25 \mu \mathrm{m}$, composed of iron nitrides, has been identified. The presence of copper prevenient from the electrode has been also detected. It has been proposed that when the plasma channel is dissipated, nitrogen ions imprisoned within the plasma channel are implanted into the workpiece surface. The technique was named nitriding by electrical discharges (NED) [13].

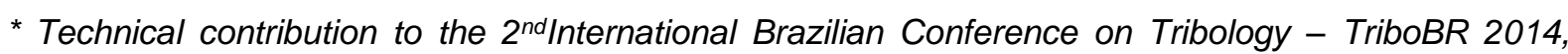
November $3^{\text {rd }}$ to $5^{\text {th }}, 2014$, Foz do Iguaçu, PR, Brazil. 


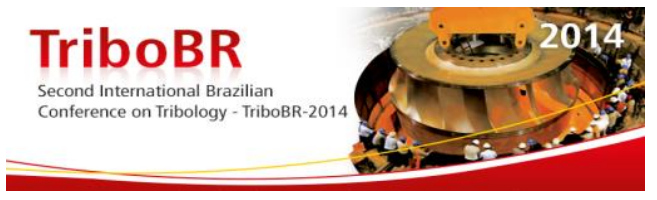

This paper aims to correlate the chemical and metallurgical modifications due to NED of AISI 4140 steels with hardness profiles and elastic modulus measurements, in order to help elucidate the mechanisms involved in this nitriding process.

\section{MATERIALS AND METHODS}

Nitrogen enrichment of the samples was carried out using electrical discharges produced by a conventional die-sinking EDM equipment, shown schematically Figure 1a. However, an auxiliary tank manufactured using AISI 304 stainless steel was adapted inside the original tank, as shown Figure 1b, to avoid contamination of the dielectric fluid. The tool electrodes were manufactured in electrolytic copper, external diameter of $22 \mathrm{~mm}$ and length of $25 \mathrm{~mm}$.

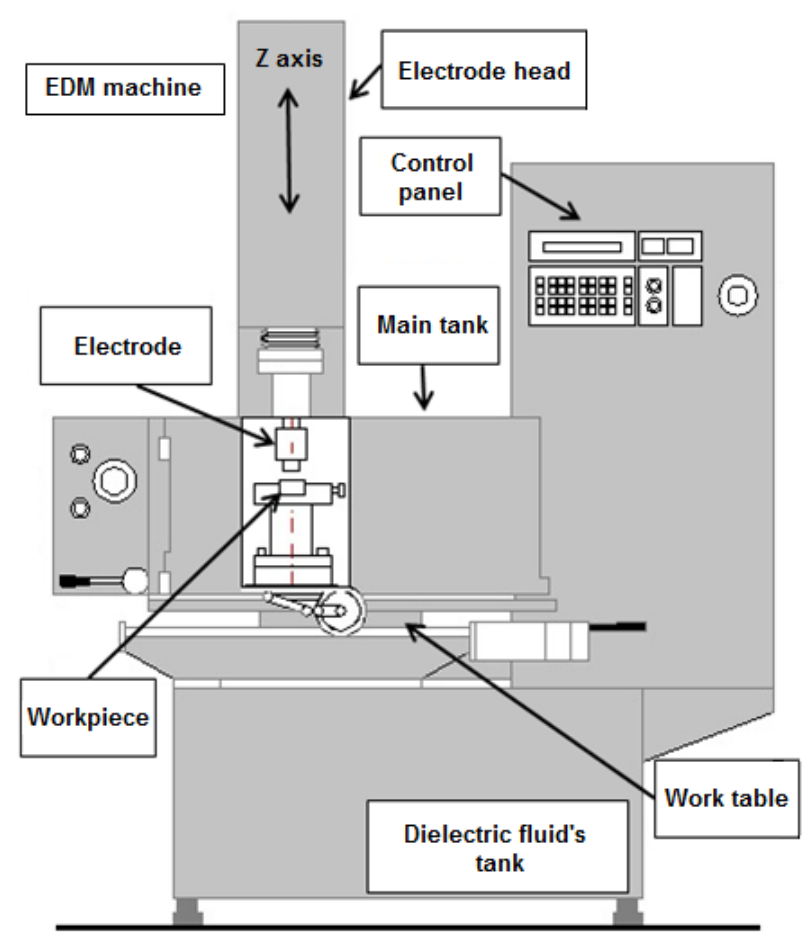

(a)
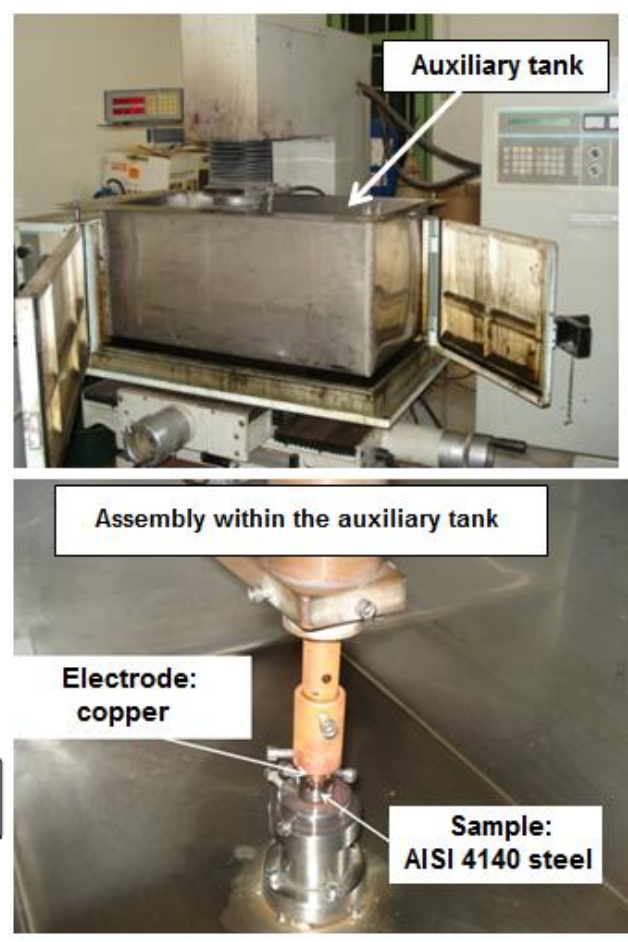

(b)

Fig. 1. EDM equipment: (a) schematics; (b): auxiliary tank adapted to the original equipment.

The workpiece electrodes (samples to be enriched) were manufactured using AISI 4140 steel cylinders with diameter of $19 \mathrm{~mm}$ and length of $12 \mathrm{~mm}$. The cylindrical workpieces were cut transversally before the EDM tests, which were then reassembled together as one cylindrical workpiece during the tests. The aim was to allow cross sections of the samples to be analysed after enrichment without damaging the modified surface with posterior cutting. In order to verify if the gap between the two semi-cylindrical halves would interfere with the process, some samples were also tested without transversal cutting, as one single cylinder, but no significant differences were detected on hardness, roughness and structure of the modified surfaces. Therefore, the use of two transversally cut halves as a single workpiece has been adopted as an adequate methodology.

The dielectric fluid was a solution of urea in deionized water at a proportion of $10 \mathrm{~g} / \mathrm{l}$. The conductivity of this solution was measured as $1455 \mu \mathrm{S} / \mathrm{cm}$, compared with 4 $\mu \mathrm{S} / \mathrm{cm}$ for deionized water [13]. Although this value is higher than that of dielectric fluids usually used in EDM, acceptable machining conditions were obtained. For

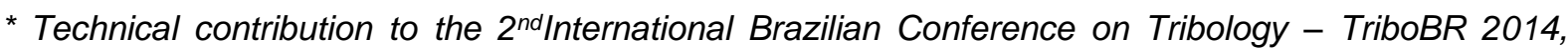
November $3^{\text {rd }}$ to $5^{\text {th }}$, 2014, Foz do Iguaçu, PR, Brazil.
} 


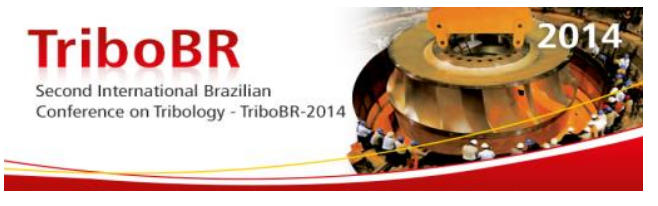

comparison, tests were also carried out using pure deionized water. Three repetitions were carried out for each condition tested.

The operational parameters used for the enrichment tests are presented in Table 1.

Table 1. Operational parameters used in the NED tests.

\begin{tabular}{ll}
\hline Tool polarity & Negative \\
\hline Voltage & $110 \mathrm{~V}$ \\
\hline Current & $30 \mathrm{~A}$ \\
\hline Pulse time ( $\left.\mathrm{T}_{\text {on }}\right)$ & $100 \mu \mathrm{s}$ \\
\hline $\mathrm{T}_{\text {on }}$ / cycle duration $(\%)$ & $50 \%$ \\
\hline Machining time & $5 \mathrm{~s}$ \\
\hline Length of intermittent tool drawback & $1 \mathrm{~mm}$ \\
\hline Interval between machining and tool drawback & $0 \mathrm{~s}$ \\
\hline
\end{tabular}

After the EDM tests, four microhardness profiles were obtained in each of the two cross sections of the specimens using a Knoop indenter, normal load of $98 \mathrm{mN}$ during $15 \mathrm{~s}$. The first measurement was at a depth of $5 \mu \mathrm{m}$ from the surface, with spacing between indentations of $10 \mu \mathrm{m}$, down to a depth of $100 \mu \mathrm{m}$. were used to produce the indentations.

The microstructure of the cross sections after NED was analysed using optical microscopy after conventional metallographic preparation and etching with Nital $2 \%$.

X-ray diffraction (XRD) was used to detect and identify the types of nitrides in the surfaces after NED. Specifications of the diffractometer and operational conditions are described in Table 22. The measurements were carried out perpendicularly to the machined surface. In sequence, a $5 \mu \mathrm{m}$ layer was removed from the machined surface by polishing with diamond paste using abrasive sizes of 3 and $1 \mu \mathrm{m}$. The control of the depth of material removed during polishing was carried out by a dial gauge with resolution of $1 \mu \mathrm{m}$. This procedure was repeated five times, until a total thickness of $25 \mu \mathrm{m}$ was removed.

Table 2. XRD conditions.

\begin{tabular}{|l|c|}
\hline Radiation & Cu-Ka \\
\hline Voltage & $40 \mathrm{kV}$ \\
\hline Current & $30 \mathrm{~mA}$ \\
\hline Scanning mode & Fixed time \\
\hline Scanning spacing & $0.02^{\circ}$ \\
\hline Scanning speed & $2^{\circ} / \mathrm{min}$. \\
\hline Initial angle $(2 \theta)$ & $30^{\circ}$ \\
\hline Final angle $(2 \theta)$ & $80^{\circ}$ \\
\hline
\end{tabular}

Nanoindentation tests were used to estimate the Young's elastic modulus of the surfaces after NED, using a Berkovich indenter, normal load of $\mathrm{mN}$, time $=10 \mathrm{~s}$.

\section{RESULTS AND DISCUSSION}

A typical optical micrograph of a cross section of a sample after NED is shown in Figure 2. Three regions were identified: a Heat Affected Zone (HAZ), a Recast Layer $(R L)$, and an intermediate zone between $R L$ and $H A Z$. The $H A Z$ and the $R L$ are typical of surfaces conventionally machined by EDM. It is hypothesized that the intermediate zone constitutes a nitrided layer. This figure also shows Knoop

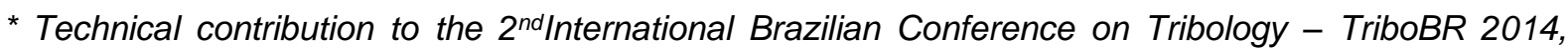
November $3^{\text {rd }}$ to $5^{\text {th }}, 2014$, Foz do Iguaçu, PR, Brazil.
} 


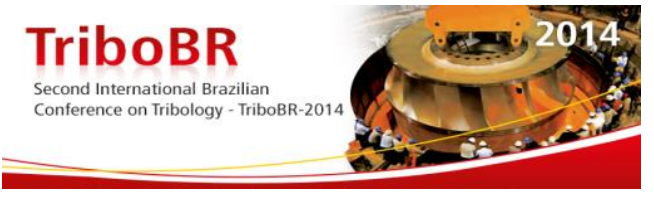

indentations from the microhardness profiles, which increase in size as the distance from the surface increases.

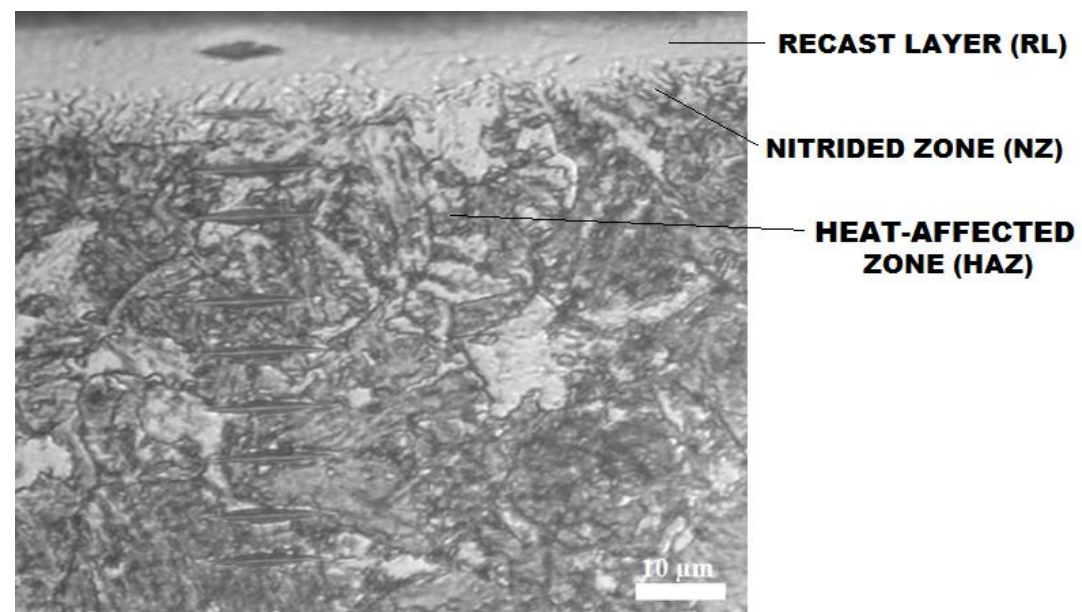

Fig. 2. Optical microscopy of a cross section of a sample after NED, showing the Knoop indentations produced to obtain the microhardness profile.

Table 3 summarizes average values of Knoop microhardness at increasing depths from the surface. Each value represents an average of eight measurements and includes the calculated standard deviation (SD). For comparison, average values obtained for a sample using deionized water as dielectric fluid is also presented. EDM resulted in surface hardening for both dielectric fluids. This result is not surprising, since the high temperatures and rapid cooling rates involved in EDM may lead to the formation of martensite down to depths of around $40 \mu \mathrm{m}$, as confirmed by optical microscopy of the cross sections after EDM. Below that, the matrix is composed of ferrite and perlite.

However, microhardness values were larger after EDM containing urea in the dielectric fluid down to a depth of $20 \mu \mathrm{m}$. After that, the differences due to presence of a nitrogen source were no longer significant. This corroborates the hypothesis of a contribution of iron nitrides towards further surface hardening in addition to that promoted by surface heat treatment. Therefore, nitrides seem to increase the hardness of the recast layer and to create a nitrided layer between this and the heat affected zone. Also, since the hardness of the $R L$ is larger than that of the HAZ, it is believed that the amount of nitrides is larger in the $R L$ than in HAZ.

Table 3. Average values of Knoop microhardness at increasing depths from the surface; $98 \mathrm{mN}, 10 \mathrm{~s}$.

\begin{tabular}{lrr} 
Position & \multicolumn{2}{c}{ Microhardness $\left(\mathbf{k g f} / \mathbf{m m}^{2}\right)$} \\
\cline { 2 - 3 }$)$ & \multicolumn{1}{c}{ Deionized water } & Deionized water + urea \\
\hline 5 to 10 & $679 \pm 171$ & $925 \pm 43$ \\
\hline 11 to 20 & $722 \pm 181$ & $879 \pm 60$ \\
\hline 21 to 30 & $660 \pm 209$ & $526 \pm 95$ \\
\hline 31 to 40 & $465 \pm 109$ & $398 \pm 59$ \\
\hline 41 to 50 & $361 \pm 56$ & $357 \pm 50$ \\
\hline 51 to 60 & $373 \pm 65$ & $376 \pm 60$ \\
\hline 61 to 70 & $394 \pm 67$ & $403 \pm 18$ \\
\hline 71 to 80 & $344 \pm 56$ & $386 \pm 14$ \\
\hline 81 to 90 & $396 \pm 32$ & $357 \pm 39$ \\
\hline 91 to 100 & $392 \pm 36$ & $376 \pm 11$ \\
\hline
\end{tabular}

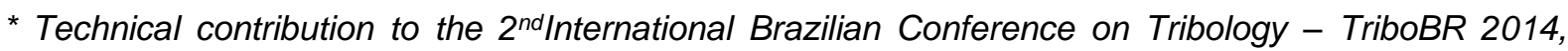
November $3^{\text {rd }}$ to $5^{\text {th }}, 2014$, Foz do Iguaçu, PR, Brazil.
} 


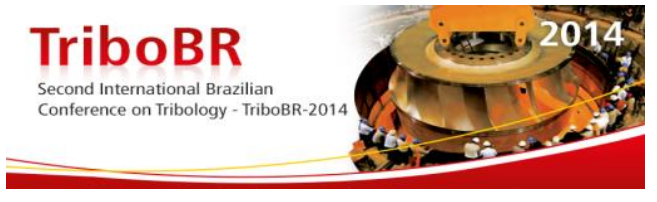

The values of elastic modulus $(E)$ calculated from nanoindentation tests in the different regions of the cross sections after NED are summarized in Table 4. A slight increase of $E$ was observed in the $R L$ and $N Z$ when compared with the matrix, again suggesting change in chemical composition.

Table 4. Young's elastic modulus $(E)$ in the different regions of a AISI 4140 steel sample after NED.

\begin{tabular}{llll}
\hline & $\mathbf{R L}$ & $\mathbf{N Z}$ & Matrix \\
\hline $\boldsymbol{E}, \mathbf{G P a}$ & $196 \pm 5$ & $191 \pm 4$ & $179 \pm 10$ \\
\hline
\end{tabular}

The findings above are confronted with X-ray diffraction results previously presented in [13]. Fig. 3 shows X-ray diffraction (XRD) results for AISI 4140 steel before NED (reference) and after NED. For the specimens produced using NED, the diffractograms were obtained after sequential removal of depths of $5 \mu \mathrm{m}$.

This figure shows that all diffractograms present peaks relative to (110), (200), (211), (220) and (310) crystallographic planes of $\alpha$-Fe. After removing $25 \mu \mathrm{m}$ of the sample treated by NED, the diffractogram obtained was similar to that of the reference sample, confirming that for this depth surface nitriding was negligible. For the other diffractograms, peaks relative to $\mathrm{Cu}$ are observed, indicating enrichment of the workpiece electrode with material from the tool electrode, as observed by other authors [2,7,8]. GDEOS measurements of similar samples shown in [13] confirm that the amount of $\mathrm{N}$ found in the treated surfaces was substantially higher than the amount of $\mathrm{Cu}$. Another important feature is the reduction of the intensities of the peaks relative to the nitrides as the depth from the surface increases. Peaks relative to different types of iron nitrides (FeN (111) and (220); $\varepsilon-\mathrm{Fe}_{2-3} \mathrm{~N}(110)$; and $\mathrm{Fe}_{2} \mathrm{~N}$ (202)) were also identified and their intensity were higher than those observed for $\mathrm{Cu}$, suggesting a more efficient enrichment mechanism when the source of the alloying element is dissolved in the dielectric fluid than when present in the tool electrode. It is unlikely that those peaks are relative to the $\mathrm{y}^{\prime}-\mathrm{Fe}_{4} \mathrm{~N}$ nitride, which is an equilibrium phase predicted in the $\mathrm{FeN}$ phase diagram, since very high temperatures $\left(>10.000^{\circ} \mathrm{C}\right)$, low pressures $(200 \mathrm{bar})$ and short times $\left(10^{-6} \mathrm{~s}\right)$ are involved, which do not represent equilibrium conditions. In another work [14], when the copper electrode was substituted by a graphite electrode, the introduction of carbon ions in the plasma channel apparently changed the thermodynamics of the process and $\mathrm{y}^{\prime}-\mathrm{Fe} 4 \mathrm{~N}$ nitride was detected.

\footnotetext{
* Technical contribution to the $2^{\text {nd }}$ International Brazilian Conference on Tribology - TriboBR 2014, November $3^{\text {rd }}$ to $5^{\text {th }}, 2014$, Foz do Iguaçu, PR, Brazil.
} 

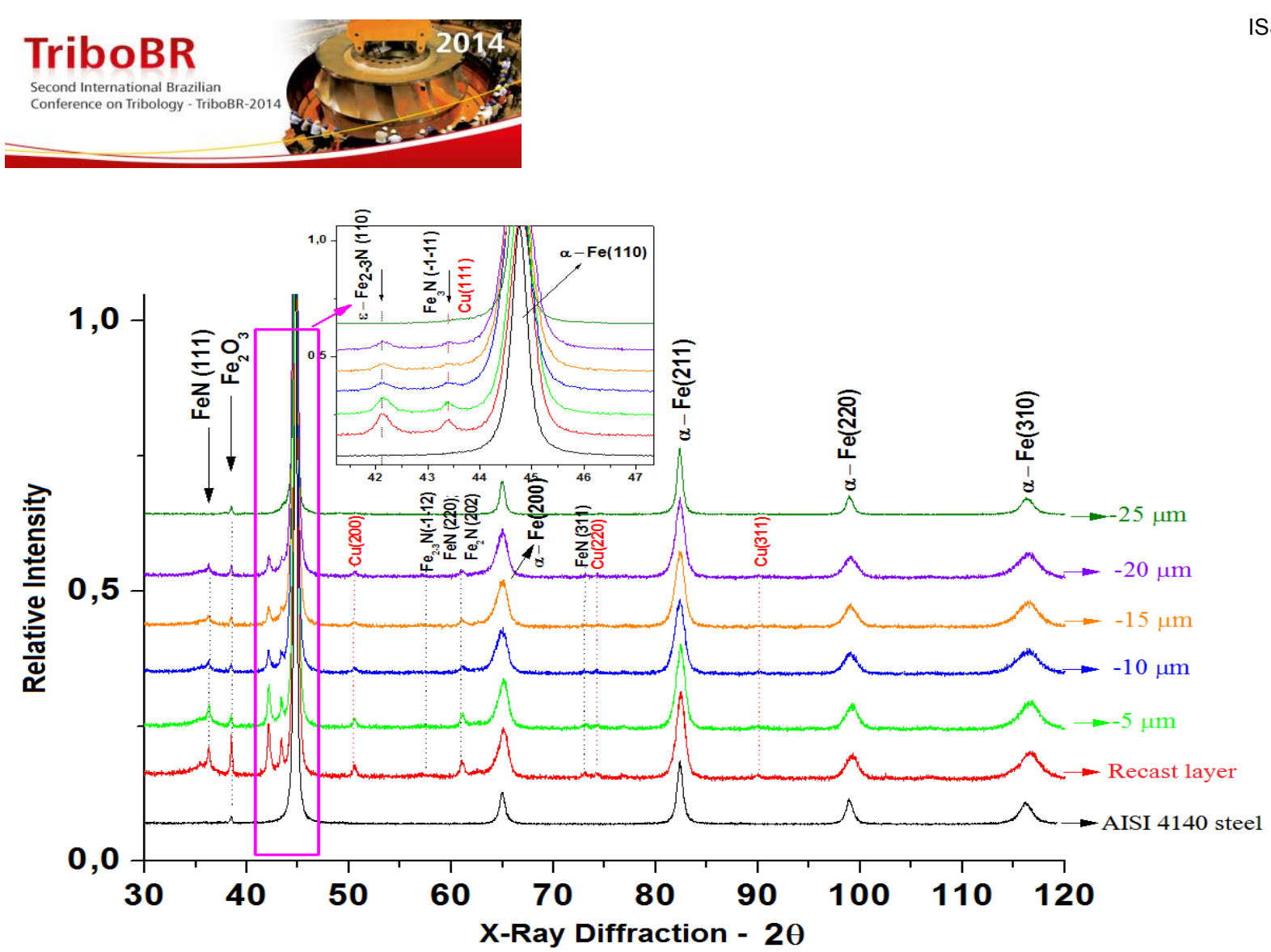

Fig. 3. X-ray patterns for AISI 4140 steel, before NED (reference), and after NED at increasing depths from the surface, from [13].

In order to quantify the reduction in the intensity of the nitride peaks as the depth from the surface increases, the intensities of the peaks were identified for each type of nitrides. Since the maximum peak was identified for $\alpha$-Fe (110), its intensity was taken as 1 and the relative intensities of the nitride peaks were calculated in relation to this for each depth, as shown in Figure 3. This graph shows that the intensity of the nitride peaks decays approximately exponentially with the increase of the depth from the surface. Similarly, GDEOS measurements [13] had shown an exponential decay of the amount of nitrogen with increasing depths from the surface. It can be also pointed out that the decay in the intensity of the peaks was more pronounced for $\varepsilon-\mathrm{Fe}_{2}-3 \mathrm{~N}$ than for $\mathrm{FeN}, \mathrm{Fe}_{2} \mathrm{~N}$ e $\mathrm{Fe}_{3} \mathrm{~N}$.

The physical model proposed in this work suggests that the dissolution of urea in the dielectric fluid (deionized water) is responsible for surface nitriding observed in AISI 4140 steel samples subjected to EDM. According to this model, the very high temperatures involved in the EDM promote urea decomposition, liberating nitrogen, which is then ionized and arrested within the plasma channel. Due to its high kinetics energy, nitrogen ions within the plasma are then implanted into the workpiece surface. As the depth from the surface increases, the amount of nitrogen implanted into the material decreases. For AISI 4140 steel, the maximum depth for which nitriding occurred was inferior to $25 \mu \mathrm{m}$. The nitrided depth has been found to be larger for Ti6Al4V alloys [9, 10], but the reasons for this still need to be investigated.

\section{CONCLUSIONS}

EDM tests using urea dissolved in deionized water as dielectric fluid were carried out in AISI 4140 steel samples. The results confirmed surface nitriding, which increased microhardness and elastic modulus of the treated surfaces.

\footnotetext{
* Technical contribution to the $2^{\text {nd }}$ International Brazilian Conference on Tribology - TriboBR 2014, November $3^{\text {rd }}$ to $5^{\text {th }}, 2014$, Foz do Iguaçu, PR, Brazil.
} 


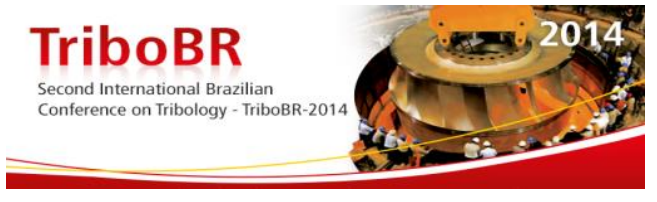

The nitrided zone, which occurred down to a depth of approximately $25 \mu \mathrm{m}$ for the samples with addition of urea, was not present when the samples were treated without urea.

A heat affected zone was also observed below the nitrided zone, down to a depth of approximately $40 \mu \mathrm{m}$, which was present independently of the addition of urea to deionized water.

The intensity of the peaks that identified the presence of nitrides in XRD measurements decayed approximately exponentially with the increase of the depth from the treated surface.

\section{Acknowledgments}

The authors are grateful to Prof. Raimundo Lora Serrano (Physics Institute, UFU, Brazil) for invaluable help with the XRD analysis. FAPEMIG, CAPES and CNPq (Brazil) are also thanked for financial support.

\section{REFERENCES}

1 McGeough JA. Advanced Methods of Machining. London: Chapman and Hall; 1988.

2 Simao J, Lee HG, Aspinwall DK, Dewes RC, Aspinwall EM. Workpiece surface modification using electrical discharge machining. International Journal of Machine Tools \& Manufacture. 2003;43:121-128.

3 Kumar S, Singh R, Singh TP, Sethi BL. Surface modification by electrical discharge machining: A review. Journal of Materials Processing Technology. 2009;209:3675-3687.

4 Yasar H, Ekmekci B. Ti-6Al-4V Surfaces in SiC Powder Mixed Electrical Discharge Machining, in: K.M. Gupta (Ed.) Material Science and Engineering Technology li, 2014, pp. 226-230.

5 Bhattacharya A, Batish A, Kumar N. Surface characterization and material migration during surface modification of die steels with silicon, graphite and tungsten powder in EDM process. Journal of Mechanical Science and Technology. 2013;27:133-140.

6 Mello JDB, Goncalves JL, Jr. HL. Costa, Influence of surface texturing and hard chromium coating on the wear of steels used in cold rolling mill rolls. Wear. 2013;302:1295-1309.

7 Stambekova K, Lin HM, Uan JY. Microstructural and Corrosion Characteristics of Alloying Modified Layer on 5083 Al Alloy by Electrical Discharge Alloying Process with Pure Silicon Electrode. Materials Transactions. 2012;53:1436-1442.

8 Suzuki T, Kobayashi S. Mechanisms of TiC layer formation on high speed steel by a single pulse in electrical discharge machining. Electrochimica Acta. 2013;114:844-850.

9 Yan BH, Tsai HC, Huang FY. The effect in EDM of a dielectric of a urea solution in water on modifying the surface of titanium. International Journal of Machine Tools \& Manufacture. 2005;45:194-200.

10 Camargo BC, Raslan AA, Costa HL. Endurecimento Superficial de Uma Liga Ti6A14V por Meio de Usinagem por Descargas Elétricas. In: V Congresso Brasileiro de Engenharia de Fabricação - COBEF; 2009; Belo Horizonte, Brazil. ABCM; 2009.

11 Silva ER, Costa HL, Raslan AA, Santos RF, Pereira GCS, Gouveia VJP. Nitriding process of SAE 4140 steel using FJEDM. In: $21^{\text {st }}$ Brazilian Congress of Mechanical Engineering; 2011; Natal, Brazil. ABCM; 2011.

12 Santos RF, Silva ER, Costa HL, Raslan AA. Nitretação por EDM de aço AISI 4140. In: 67th International ABM Congress; 2012; Rio de Janeiro, Brazil. São Paulo: ABM; 2012.

13 Santos RF, Silva ER, Costa HL, Oliveira ARF, Raslan AA. Nitriding of the AISI 4140 Steel by EDM. Torino: Vth World Tribology Congress (WTC); 2013.

14 Santos RF, Silva ER, Oliveira AR, Costa HL, Raslan AA. Electrical discharge nitriding (EDN) of AISI 4140 steel with graphite electrode. Uberlandia: VII CONEM, ABCM; 2014.

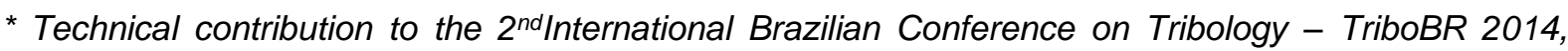
November $3^{\text {rd }}$ to $5^{\text {th }}, 2014$, Foz do Iguaçu, PR, Brazil. 